\title{
Article \\ Powder Epoxy for One-Shot Cure, Out-of-Autoclave Applications: Lap Shear Strength and Z-Pinning Study
}

\author{
Thomas Noble ${ }^{1}$, James R. Davidson $\left.{ }^{1}{ }^{(}\right)$, Christophe Floreani ${ }^{1}{ }^{\circledR}$, Ankur Bajpai ${ }^{1}{ }^{\circledR}$, William Moses ${ }^{2}$, \\ Thomas Dooher ${ }^{2}$, Alistair McIlhagger ${ }^{2}$, Edward Archer ${ }^{2}\left(\mathbb{D}\right.$, Conchúr M. Ó Brádaigh ${ }^{1}\left(\mathbb{D}\right.$ and Colin Robert ${ }^{1, *(1)}$ \\ 1 Institute for Materials and Processes, School of Engineering, The University of Edinburgh, \\ Edinburgh EH9 3FB, UK; tnoble2@ed.ac.uk (T.N.); j.r.davidson@ed.ac.uk (J.R.D.); \\ christophe.floreani@ed.ac.uk (C.F.); ankur.bajpai@ed.ac.uk (A.B.); c.obradaigh@ed.ac.uk (C.M.Ó.B.) \\ 2 Engineering Research Institute, Ulster University, Shore Road, Newtownabbey BT37 0QB, UK; \\ moses-w@ulster.ac.uk (W.M.); t.dooher@ulster.ac.uk (T.D.); a.mcilhagger@ulster.ac.uk (A.M.); \\ e.archer@ulster.ac.uk (E.A.) \\ * Correspondence: colin.robert@ed.ac.uk
}

\section{check for} updates

Citation: Noble, T.; Davidson, J.R.; Floreani, C.; Bajpai, A.; Moses, W.; Dooher, T.; McIlhagger, A.; Archer, E.; Ó Brádaigh, C.M.; Robert, C. Powder Epoxy for One-Shot Cure, Out-ofAutoclave Applications: Lap Shear Strength and Z-Pinning Study. J. Compos. Sci. 2021, 5, 225. https:// doi.org/10.3390/jcs5090225

Academic Editor:

Francesco Tornabene

Received: 22 July 2021

Accepted: 19 August 2021

Published: 24 August 2021

Publisher's Note: MDPI stays neutral with regard to jurisdictional claims in published maps and institutional affiliations.

Copyright: (c) 2021 by the authors. Licensee MDPI, Basel, Switzerland. This article is an open access article distributed under the terms and conditions of the Creative Commons Attribution (CC BY) license (https:/ / creativecommons.org/licenses/by/ $4.0 /)$.

\begin{abstract}
Large composite structures manufactured out-of-autoclave require the assembly and bonding of multiple parts. A one-shot cure manufacturing method is demonstrated using powder epoxy. Lap shear plates were manufactured from powder epoxy and glass fiber-reinforced plastic with four different bonding cases were assessed: secondary bonding using standard adhesive film, secondary bonding using powder epoxy, co-curing, and co-curing plus a novel Z-pinning method. This work investigates the lap shear strength of the four cases in accordance with ISO 4587:2003. Damage mechanisms and fracture behavior were explored using digital image correlation (DIC) and scanning electron microscopy (SEM), respectively. VTFA400 adhesive had a load at break $24.8 \%$ lower than secondary bonding using powder epoxy. Co-curing increased the load at break by $7.8 \%$ compared to powder epoxy secondary bonding, with the co-cured and pinned joint resulting in a $45.4 \%$ increase. In the co-cured and co-cured plus pinned cases, DIC indicated premature failure due to resin spew. SEM indicated shear failure of resin areas and a large amount of fiber pullout in both these cases, with pinning delaying fracture phenomena resulting in increased lap joint strength. This highlights the potential of powder epoxy for the co-curing of large composite structures out-of-autoclave.
\end{abstract}

Keywords: co-curing; lap shear strength; powder epoxy; Z-pinning; out-of-autoclave manufacturing

\section{Introduction}

The autoclave process remains a benchmark for creating high-quality composites parts; however, it involves significant acquisition, operating, and tooling costs, especially for large parts [1]. Out-of-autoclave (OOA) manufacturing methods for composites are therefore becoming an increasingly popular alternative to the use of autoclaves, allowing part quality to be maintained whilst reducing cost and manufacturing time. The acceptance of OOA manufacturing is due to their ability to produce autoclave-quality parts without the use of an autoclave [2]. The use of OOA methods provides an opportunity for composites to be used more widely in larger structures such as wind turbine blades.

OOA-manufactured large composite structures currently require the assembly of a number of parts using an additional adhesion step due to oven size restrictions [3]. The joining of these parts generally uses one of three techniques: co-bonding, secondary bonding, and co-curing. A full review of adhesive bonding techniques has previously been completed by Budhe et al. [4]. Co-bonding involves the adhesion of an uncured composite part to a cured composite part, where the uncured adherend plus adhesive are cured together. Secondary bonding involves the adhesion of two cured composites parts. This adhesion step for secondary bonding and co-bonding generates further issues, including 
the inability to easily have uniform adhesive contact on complex bonding lines, the inherent additional time, material and labor costs associated, and the additional complication of introducing assembly stresses which affect the overall life of the composite structure [5].

Co-curing is an alternative bonding method which removes the need for an adhesive layer. Co-curing uses resin from the pre-assembled parts and produces no discernable interface due to the simultaneous cure of the assembly (parts + joint) [6]. In comparison, secondary and co-bonded joints have at least one adhesive interface, which allows the introduction of unwanted contaminants such as silicones or moisture [6]. Co-curing has a number of advantages, such as chemical bonding and increased cross-linking, improved mechanical properties, and an inherent lower cost due to reduced labor and material requirement $[6,7]$. Co-curing is seen as an attractive option due to the reduction in the number of parts, fixings, and curing cycles required $[4,8]$. This technique is used to make aircraft components; however, information on co-curing techniques is not commonly disclosed by companies [9]. Applications of co-curing in the late 1970s include the McDonnell Douglas AV-8B Strike Fighter Aircraft, where co-curing on the forward fuselage reduced part count by $63 \%$, fixings count by $62 \%$, and the weight by $25 \%$. Similarly, the use of co-curing on the landing gear fairing reduced labor hours by $20 \%$, along with a $65 \%$ reduction in part count, a $45 \%$ reduction in fastener count, and a $9 \%$ weight reduction [10]. Further examples include the effective use of co-curing in the speed brake on the F-15 fighter aircraft, and a co-cured wing created using research from the Technical Research and Development Institute of the Japan Defense Agency in the 1990s for the XF-2 fighter aircraft [11,12].

While co-curing provides the benefits mentioned previously, there are some limitations which are preventing the method from becoming more widely used in composites. Namely, as the size of the co-cured composite structure increases, it is likely that the complexity of the part may increase. This results in increased complexity of the tooling approach which has an inherent additional cost $[8,11]$. Therefore, the benefits from reduced assembly costs must be balanced against this additional cost.

In this context, one-shot (or single) cure manufacturing processing methods (RTM, Prepreg) have recently been gaining popularity in industry due to their lower cost and higher processing speed [13]. In this exploratory study, a powder epoxy system with separate melting and curing temperatures was used to highlight the co-curing benefits. The powder epoxy has several advantages which are covered in the next section, with this study intending to be an initial investigation into the effectiveness of this resin for bonding purposes, with the idea of future scalability. The lap shear cohesive strength of co-cured samples is investigated in comparison with traditional two-step cures for bonding purposes. A novel pinning technique, developed at Ulster University, has additionally been combined with the co-curing bonding method.

\section{Materials and Methods}

\subsection{Materials}

\subsubsection{Powder Epoxy}

The powder epoxy (PE6405) used in this study was developed by Swiss CMT AG (Siebnen, Switzerland) and produced by Freilacke (Bräunlingen-Döggingen, Germany). The powder system has multiple advantages, such as a low curing exotherm [14,15], which reduces the risk of thermal runaway during manufacturing of thick sections, and a low minimal viscosity $[14,15]$ for optimal wetting and minimal porosity, leading to superior mechanical properties [16-19].

Another main asset of the powder is the ability to separate the powder melting from the cure (Figure 1), enabling composite parts to be melted, pre-shaped, and consolidated without curing. This ability to melt, pre-shape, and consolidate, combined with co-curing is envisaged to help reduce the complexity of tooling required. 


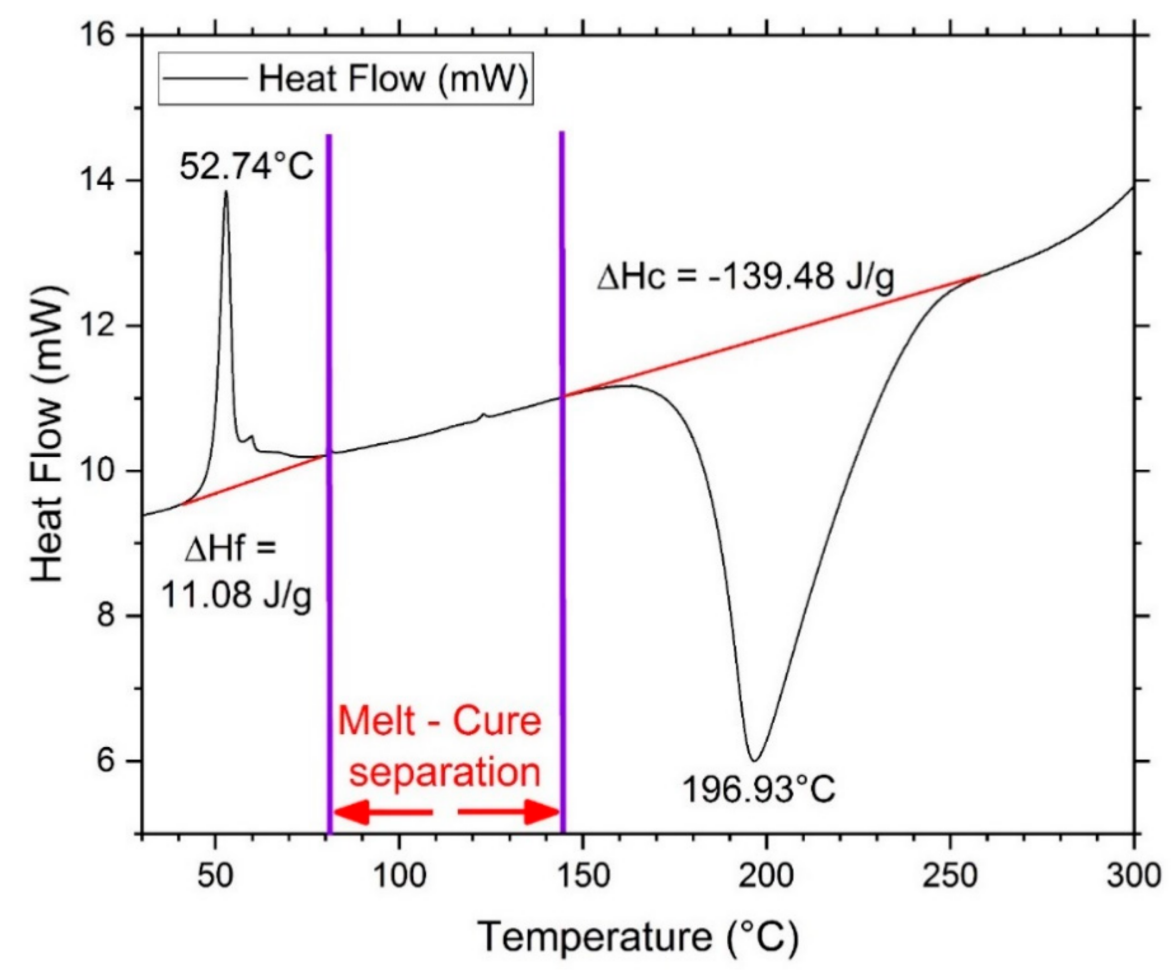

Figure 1. Differential scanning calorimetry showing a temperature sweep of $\left(20^{\circ} \mathrm{C} / \mathrm{min}\right)$ of PE6405. The temperature gap between the end of the melt and beginning of the cure is represented by purple lines [16].

The resin can be stored at room temperature and is suitable for out-of-autoclave industrial processes [16,17], as well as one-shot-cure processing, which will be demonstrated in this paper.

The powder epoxy has also been shown in previous work to have improved interlaminar fracture toughness [19] compared to untoughened liquid epoxy resins, which is very interesting as there is a linear correlation between fracture toughness and lap shear strength [20].

Finally, the manufacture of large OOA composite structures was performed previously, proving the viability of the system for this specific purpose. Indeed, in the case of the POWDERBLADE project, a 6-metre-long carbon/glass fiber hybrid wind turbine blade was manufactured by the University of Edinburgh (Edinburgh, UK) with this specific powder epoxy system [21].

\subsubsection{Glass Fibers}

As part of this study, a 591-g/m² UD stitched glass fabric from SAERTEX was used for sample manufacturing. The fabric contains $520 \mathrm{gsm}$ of $0^{\circ}$ E-glass fibers as well as $17 \mathrm{gsm}$ of polyester stitching and $54 \mathrm{gsm}$ of $90^{\circ}$ E-glass fibers [22]. UD stitched glass fabric was chosen for this initial study with a view of potential applications in standard OOA processes such as wind turbine blade manufacturing [23].

\subsubsection{Adhesive Prepreg}

The adhesive prepreg used in this study is VTFA400 from SHD Composites (Sleaford, UK). This is a toughened epoxy adhesive film within a very thin glass fiber mesh to ensure uniform thickness and minimal porosity. Adhesive prepreg is commonly used as a large area structural adhesive, for example in the aerospace industry [24]. 
2.2. Lap Shear Samples Manufacturing and Testing

2.2.1. Manufacturing and Testing Overview

A summary of the manufacturing process is provided in Figure 2.

\section{GFRP layup + powder deposited in steel 5a. Half plates assembled with bond mold into PTFE covered steel mold}

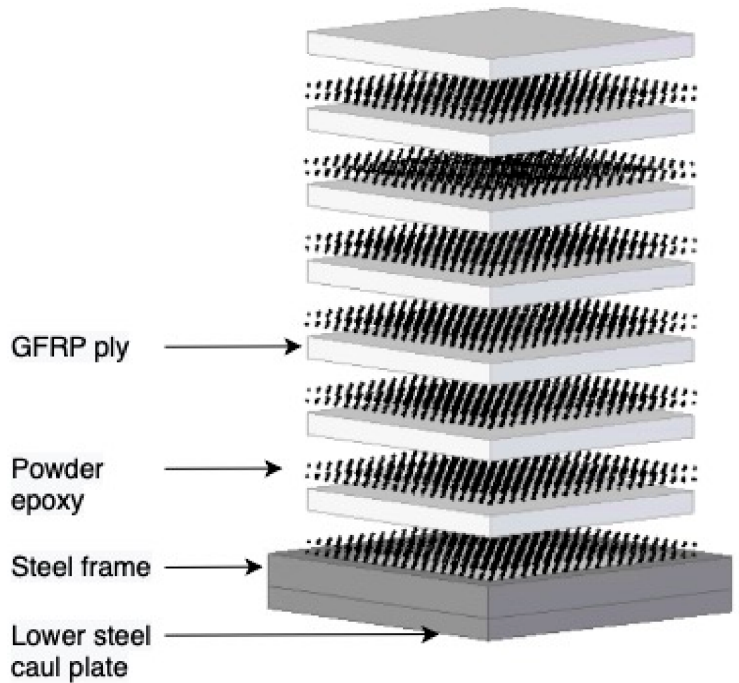

2. Upper steel caul plate placed on
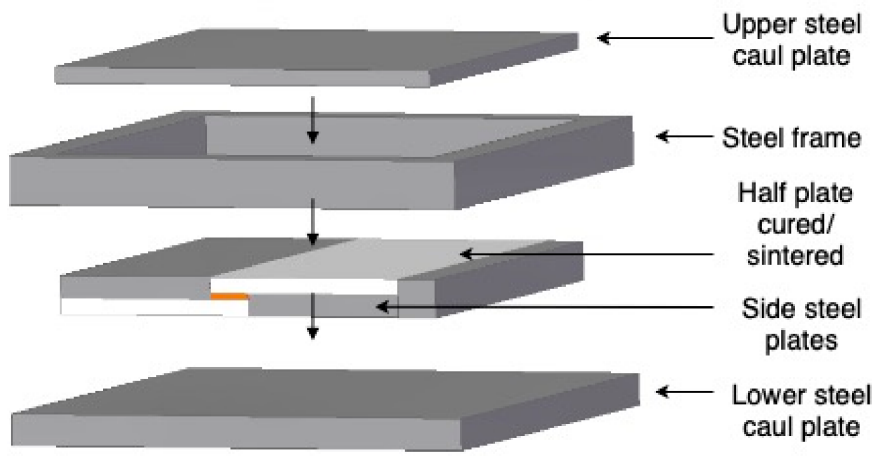

5b. Lap shear plate cross section within mold

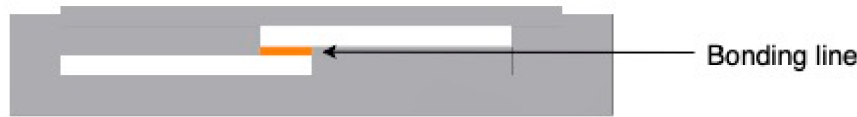
top

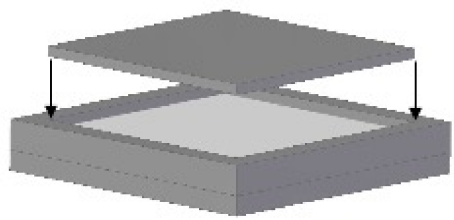

3. Sintered/ cured plate produced

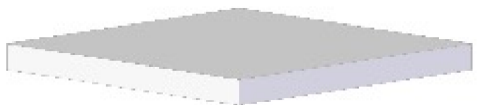

5c. Pinning of sintered lap shear plate

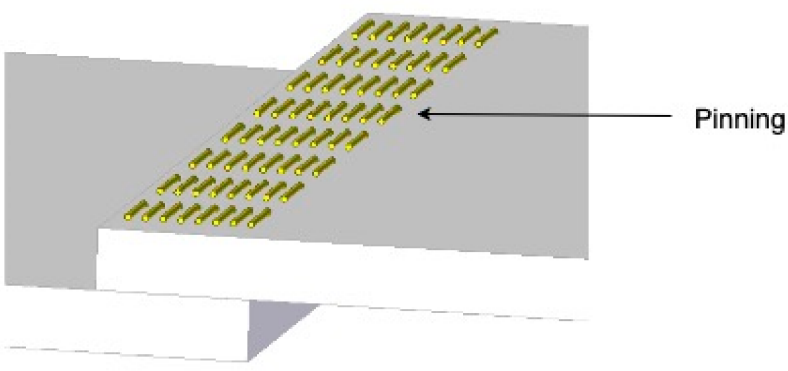

6. Lap shear plate end tabbing and sample cutting

\section{Sintered/ cured plates cut in half}

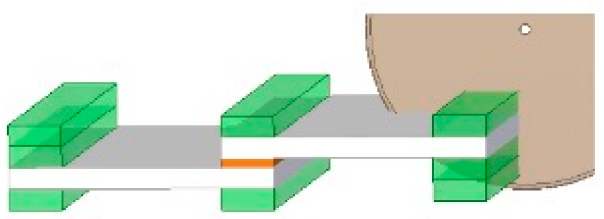

Figure 2. Initial plate and co-curing manufacturing process. Layup of plate into steel frame with upper + lower caul plate (1-2), sintering/curing of the plate (3), cutting plate in half (4), half plates assembled and bonded depending on case $(5 \mathbf{a}, 5 \mathbf{b}, 5 \mathbf{c})$, lap shear plate end tabbed and samples cut $(6)$.

Firstly, glass fiber-reinforced plastic and powder epoxy plates were produced using a previously developed manufacturing process [19].

Due to the low minimum viscosity of powder epoxy prior to gelation, the resin tends to bleed out of the composite during the sintering/curing stage. This can cause some variability in the fiber volume fraction (FVF) of the manufactured plates [19]. To solve 
this, a previously manufactured steel frame was used $(8 \mathrm{~mm}$ thick, inner dimensions of $300 \mathrm{~mm} \times 280 \mathrm{~mm}$ ) along with two steel caul plates. The frame rests on the larger lower caul plate, while the upper caul plate inserts tightly into the frame to ensure uniform pressure is exerted by the applied vacuum, and to limit resin bleed-out. For ease of removal of the cured/sintered plates, the steel caul plates were coated in TFG 250 PTFE coated glass fiber, with the frame being coated in thin TF 050AH PTFE tape.

The GFRP plies were cut to fit a steel mold (lower caul plate and frame) covered in PTFE. The powder was weighed and homogeneously sprinkled on interlayers to reach $50 \%$ FVF, ensuring good fiber wetting and an even resin distribution (step 1). The PTFE-covered steel upper caul plate was then placed on top (step 2) and the whole system was vacuum bagged and cured or only melted/sintered, depending on the sample set investigated (step 3). The sintering and curing cycles for the powder epoxy GFRP plates are provided in Figure 3.
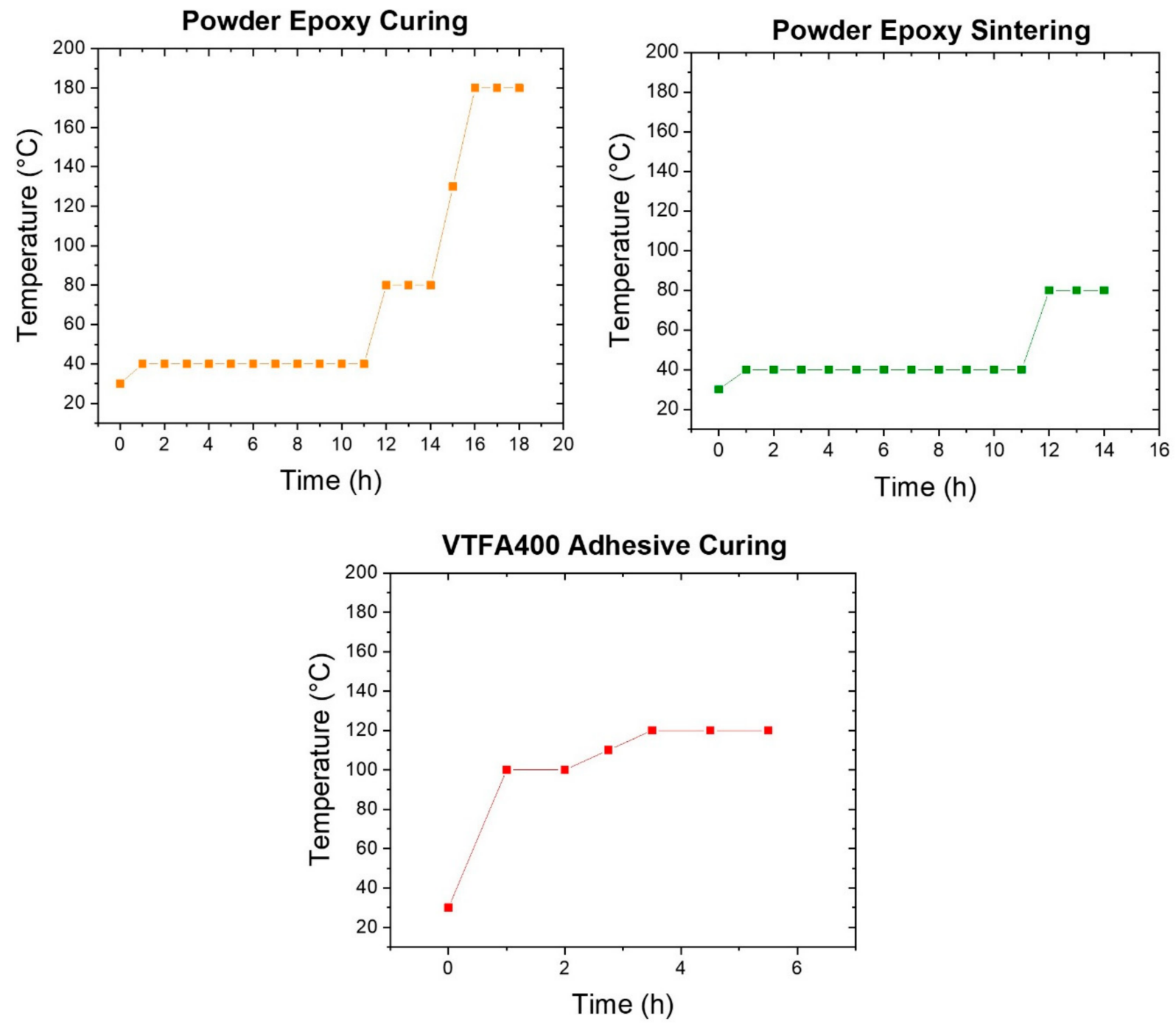

Figure 3. Curing and sintering cycles for powder epoxy and VTFA400 adhesive.

The plates were then cut in half at $90^{\circ}$ to the longitudinal direction and the edges were trimmed (step 4). At this stage, Z-pinning of two sintered half plates was completed, outlined in detail in Section 2.2.3. Plates were then placed in a PTFE covered steel mold fitting the ISO 4587 dimensions (step $5 a+5 b$ ). Figure 4 shows the sintered half plate inside the PTFE covered steel mold. 


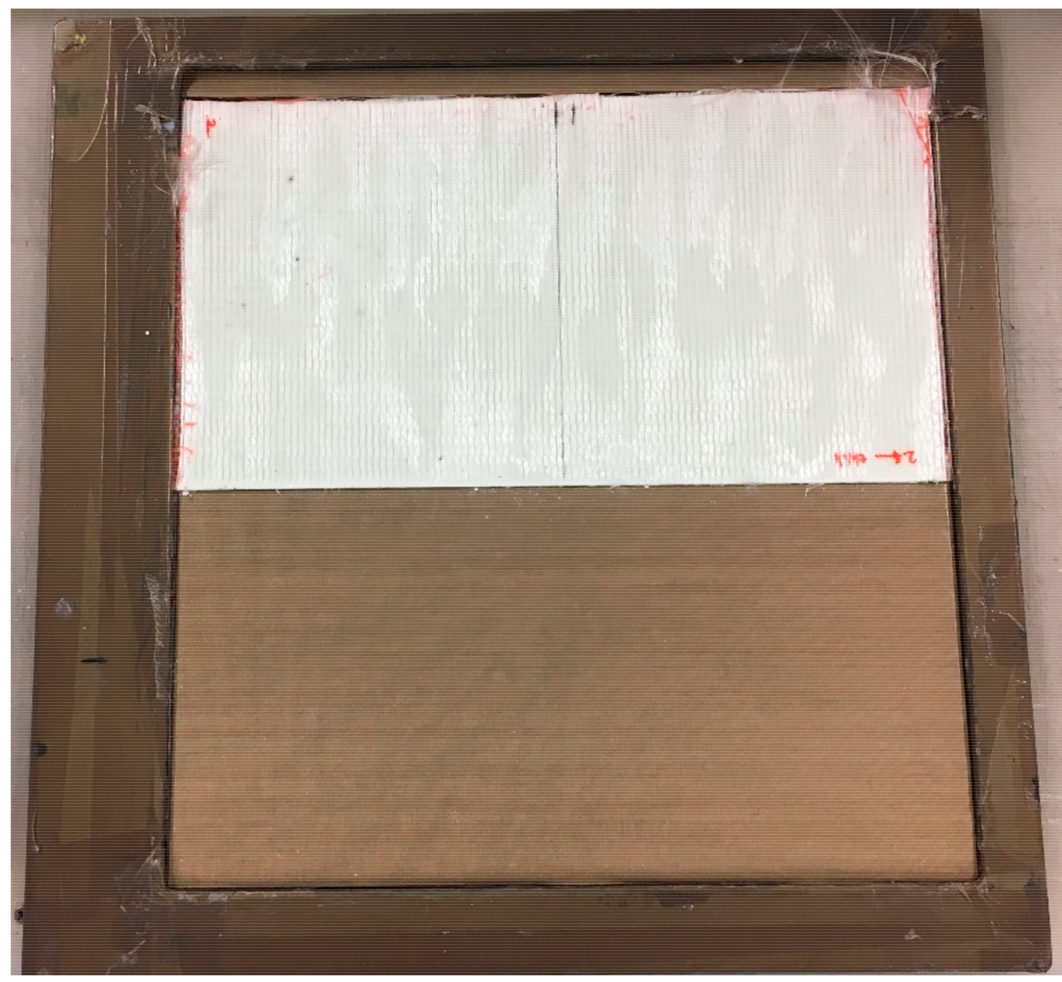

Figure 4. Sintered GFRP + powder epoxy half-plate inside steel frame.

The half plates were placed under vacuum again and bonding lines were then cured accordingly. The purpose of the side steel plates (also shown in step 5a, Figure 2) was to maintain uniform pressure on the plates and bonding line while under vacuum.

The co-cured plate is shown in Figure 5 below.

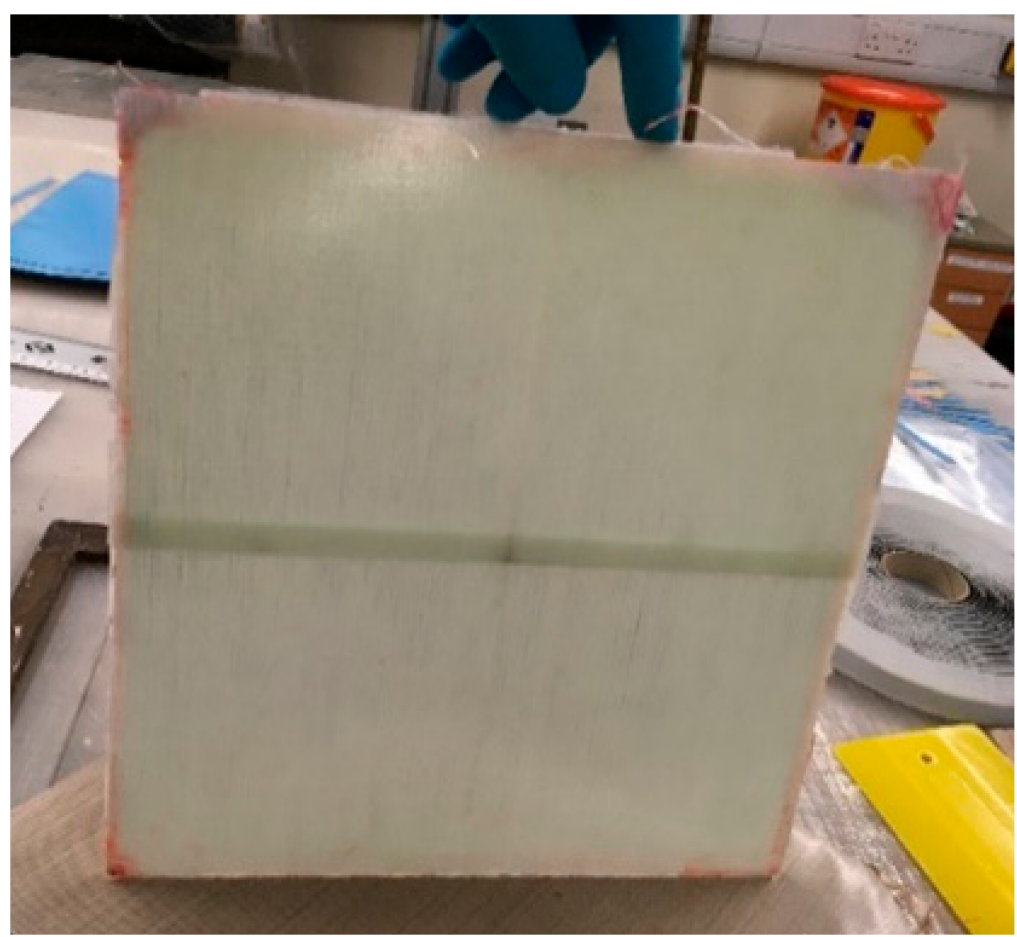

Figure 5. Photo of co-cured plate (case 3). 
Finally, the lap shear plates were cut to dimension according to ISO 4587 (step 6). During the cutting process, end tabs were applied temporarily over the bonding region with double-sided tape to reinforce and prevent premature damage to the plate and samples during cutting (Figure 6), then removed prior to testing. The double end tab configuration was used to obtain a perfect alignment during gripping, therefore preventing undesired bending of the sample during testing.

\begin{tabular}{|c|c|c|c|}
\hline End tab & & & \\
\hline & & & \\
\hline
\end{tabular}

\section{VTFA400 adhesive film}

Double sided tape

Figure 6. End tab configuration during cutting of the lap shear plates.

The co-curing cohesive strength was investigated according to ISO 4587: AdhesivesDetermination of tensile lap-shear strength of rigid-to-rigid bonded assemblies.

The lap shear strength test setup is provided in Figure 7. An INSTRON $336910 \mathrm{kN}$ universal testing system was used, and samples were tested at $2 \mathrm{~mm} / \mathrm{min}$. The temperature was maintained at a stable $22{ }^{\circ} \mathrm{C}$ in the lab throughout the tests.

\subsubsection{Sample Set Description}

Four different sets of samples were manufactured to compare their cohesive properties (Figure 8).

Case 1: The powder epoxy-based GFRP half-plates were initially cured and an adhesive prepreg (VTFA400, SHD composites), representative of industrial standard practice, was placed on the bonding line and cured.

Case 2: The powder epoxy-based GFRP half-plates were cured, and then powder epoxy was sprinkled on the bonding line and used as an adhesive.

Case 3: The powder epoxy-based sintered GFRP plate was melted and then cooled without curing, producing a vitreous-like, sintered plate which was then cut. The structural integrity of the powder epoxy sintered plate is another advantage when compared to standard uncured prepreg, which would present issues if cutting was attempted. The half-plates were then co-cured in a one-shot-cure process (Figure 5).

Case 4: The half plates were melted then pinned and finally co-cured to assess the adhesion reinforcement potential of pinned one-shot-cure samples as compared to case 3 . The sintered plates have the ability and ease to be pinned without much damage, and then the plates are melted again during their co-curing phase, allowing for a very good consolidation at the pinned locations. This consolidation is arguably better than the one a thermoplastic would be able to achieve due to a very low viscosity. The pinning process is described in detail in Section 2.2.3.

The lap shear sample cross sections were checked before testing to check for macroscopic inhomogeneities, of which none were found. Resin overflows were observed in cases 3 and 4, a standard behavior associated with co-curing. 


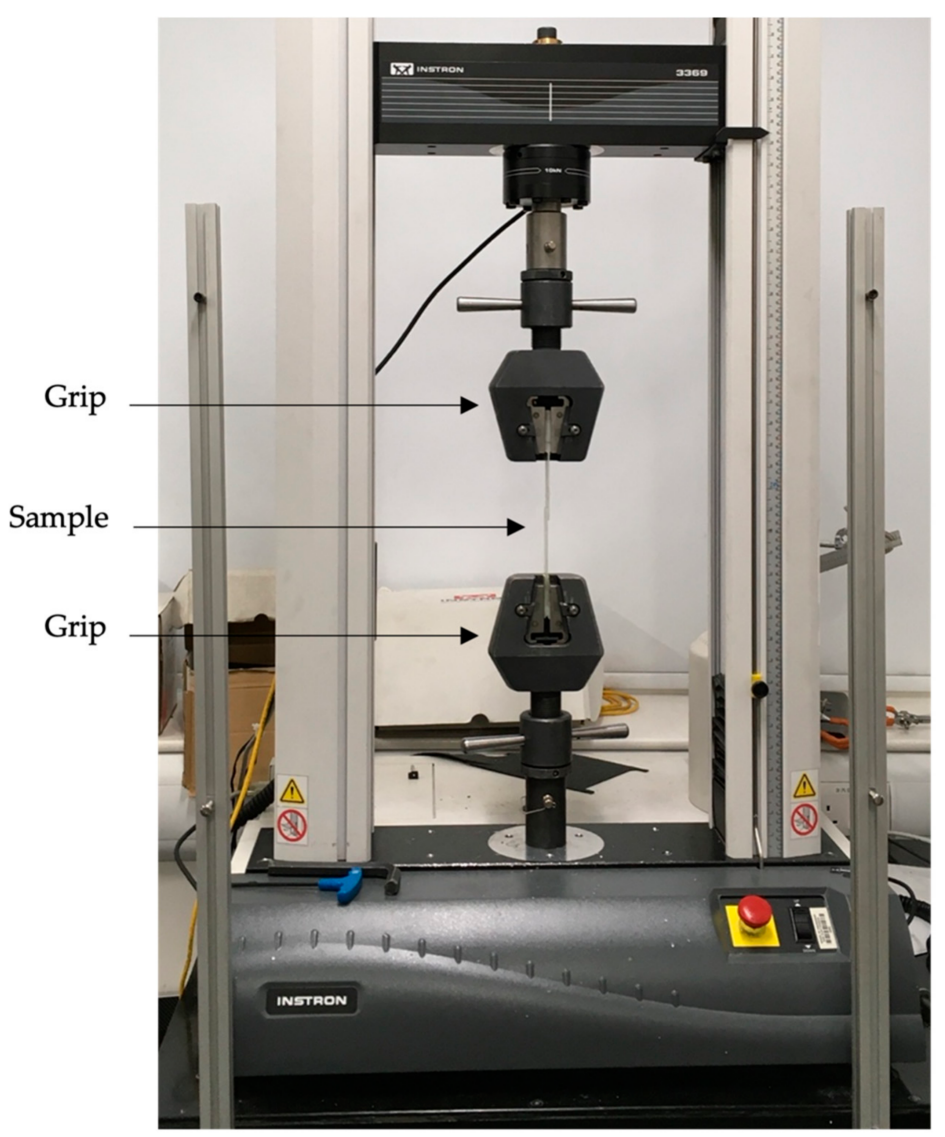

Figure 7. Lap shear strength test setup on an INSTRON $10 \mathrm{kN}$ universal testing system.

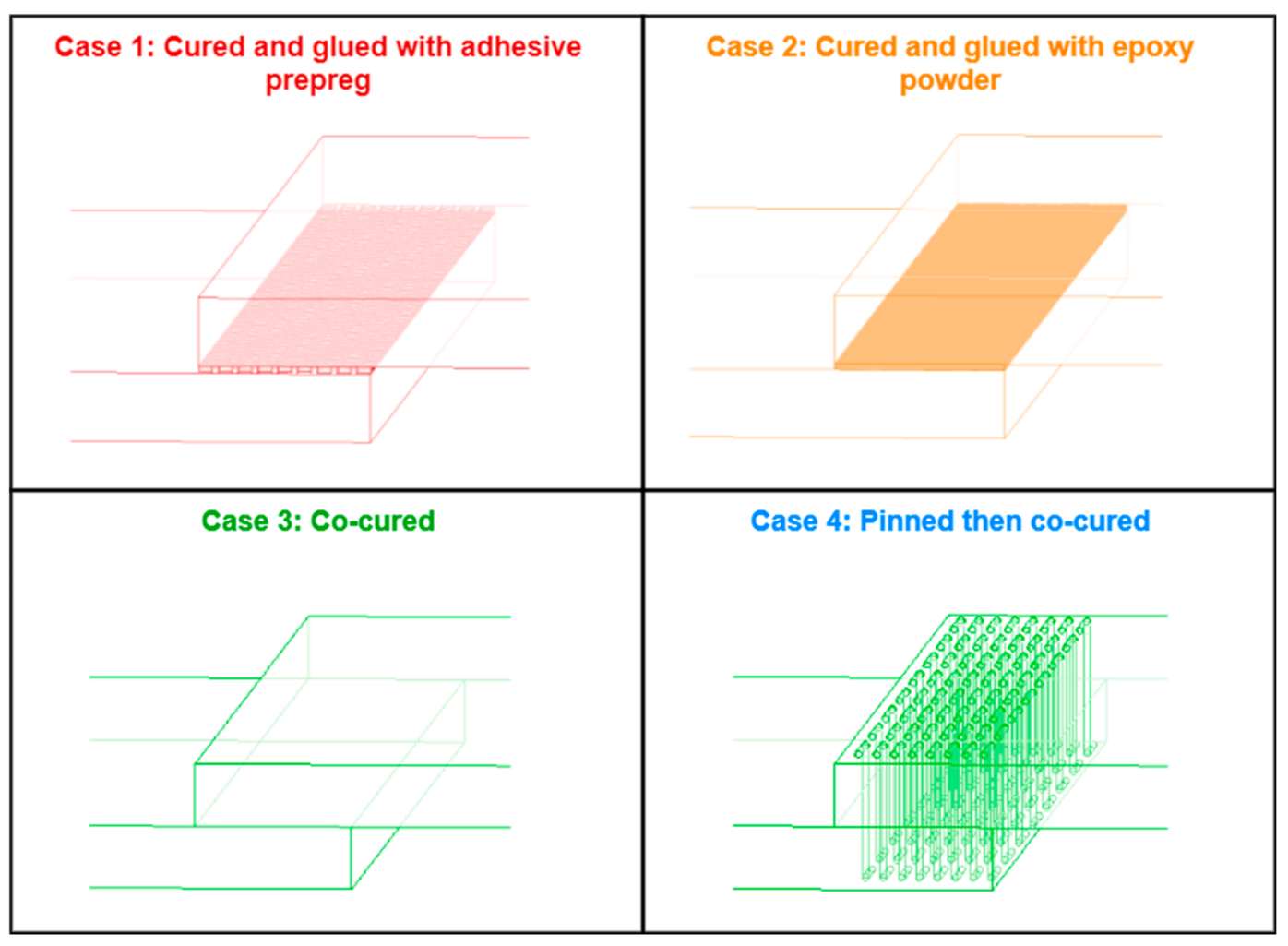

Figure 8. Schematics of the four sets of lap shear samples manufactured. 


\subsubsection{Pinning}

A novel technique for providing through-thickness reinforcement was developed at Ulster University through the EPSRC Future Composites Manufacturing Research Hub. The method involved using a nylon/carbon filament which was placed through the thickness of the preform using a veterinary needle and trimmed to length. Once the desired array of pins was placed, they were treated via compression with hot plates, causing the extended ends of the pins to lie flat against the surface of the fabric, which, once cool, binds it together [25].

In this study, the filament used was a commercial PA6-based 3D printing filament by Markforged ${ }^{\circledR}$. There are several options available, differing primarily in the material used for the fiber reinforcement. In this work, the filament used was KB-AB-50 which comprises a Kevlar based reinforcement. Figure 9:

The pinning process can be broadly described as follows, with the steps illustrated in

1. The fiber lay-up to be pinned was placed into a clamping frame which provides a fixed back-stop distance which can be adjusted by the addition of plates under the parts.

2. The filament was threaded through an 18 Birmingham Gauge veterinary needle that was mounted in a 3D printed handle for operator convenience.

3. The needle was pressed through the fiber in the desired locations.

4. The filament was then gently threaded through the needle until it hits the backstop, this provides a consistent excess length on the underside of the part.

5. The needle was then withdrawn whilst holding the filament in place. The closing of the fibers around the needle provides a light frictional force holding the filament in place.

6. The filament was then cut above the part to match the backstop distance.

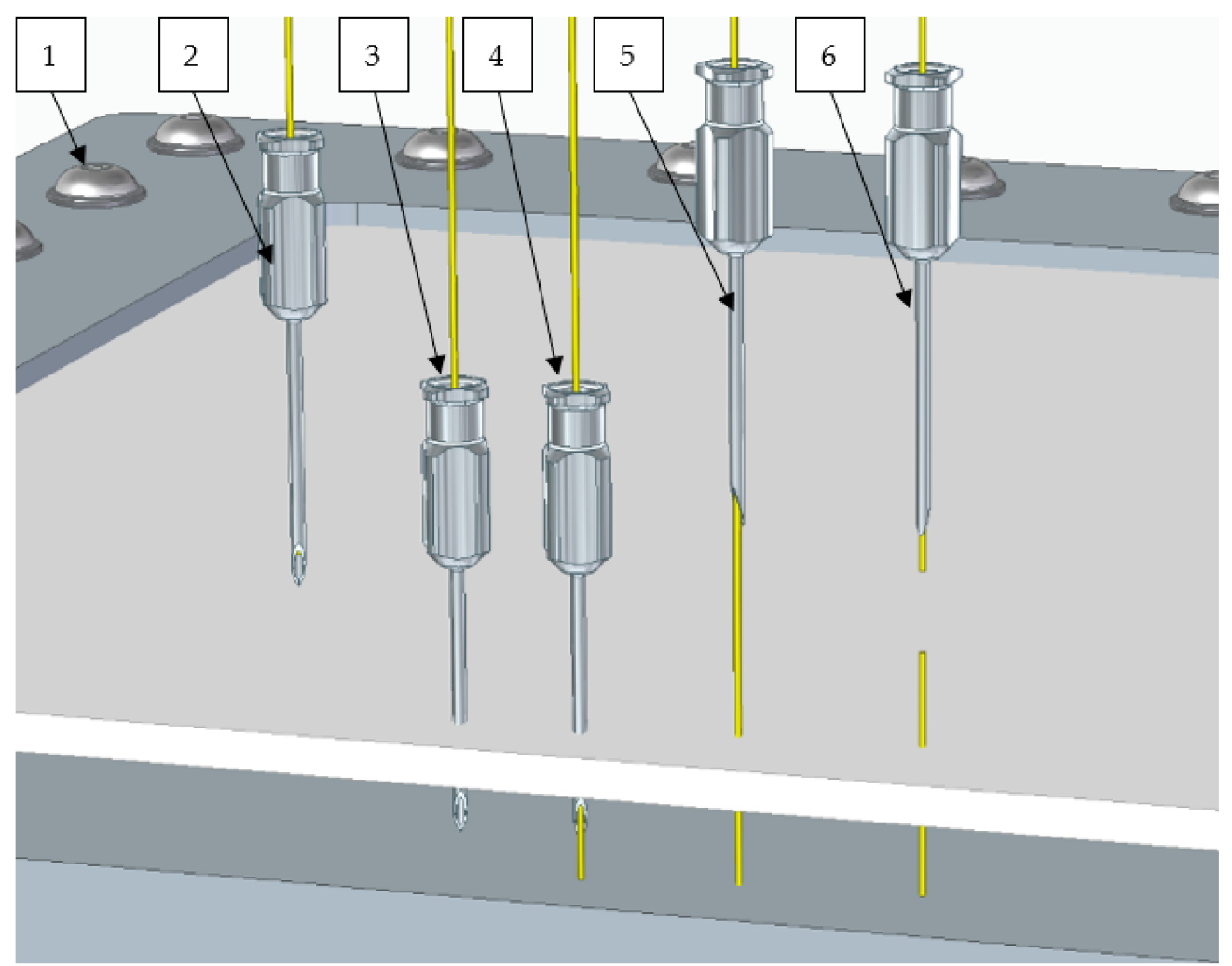

Figure 9. Representative image of the main steps of the pinning process. 
Once the desired array of pins was placed, the fiber was then subjected to a hot-press process. The tool is first heated to $150{ }^{\circ} \mathrm{C}$ in an oven. The fiber was then placed into the hot tool and the tool clamped up whilst at temperature. This has the dual effect on both bending and flattening the ends of the pins against the part, but also compressing the part to the correct thickness for infusion.

In this study however, the technique was modified to satisfy the need to maintain alignment of the overlapping sections for the lap-shear samples. This was achieved by leaving the fiber in the clamping frame and using a 2-stage process. This modified process can be described as follows:

1. In Press 1, a support plate is placed underneath the part (a). This prevents pushthrough of the pins.

2. A press-plate is heated in an oven to $150{ }^{\circ} \mathrm{C}$, placed on the upper surface of the part, and left to cool to ambient temperature overnight (b \& c). The mass of this plate provides the necessary pressure to deform and flatten the pin ends. The flattening of the pins is illustrated as steps a, b \& c in Figure 10.

3. Once the first side has cooled, the fixture is inverted with the support plate now placed against the flattened pins.

4. The process described for Press 1 is repeated for the underside of the part (Press 2: a-c).

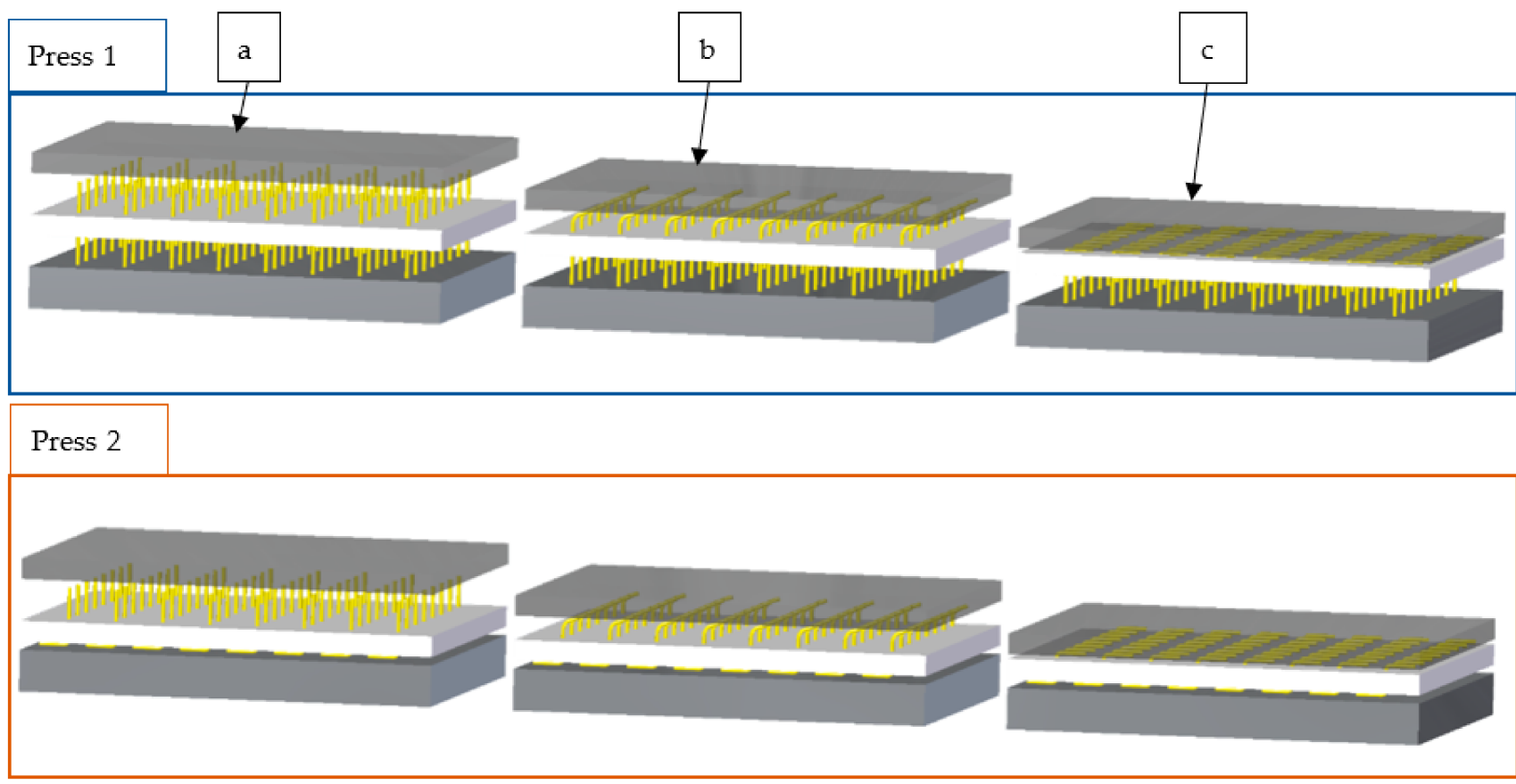

Figure 10. Graphical representation of the 2-step press process.

After this process was completed, the plate was removed from the clamping frame and subjected to the same curing cycle, as described in the manufacturing overview.

\subsubsection{Pinning Review}

The exploratory pinning process for these parts presented some challenges compared to the previous work on dry fibers that was conducted at Ulster University.

The first challenge was the toughness of the sintered epoxy preventing the penetration of the fibers by the needle. This was solved by gently introducing cracks within the epoxy in the region to be pinned. Some of the epoxy was lost with this process; however, this was primarily in the form of dust on the outer surface with the fibers preventing egress of epoxy within the part. 
The second challenge was the overlap of the pinning area. Previous work had centered primarily around pinning the full area of the plaque without the concerns of overlap presented by the geometry of the ISO 4587 specimens.

To overcome this, the fibers were placed into the clamping frame with spacer plates. These plates prevented pinning in the area outside of the overlap region whilst allowing proper pass-through in that region and supported the fibers, as shown in Figure 11.

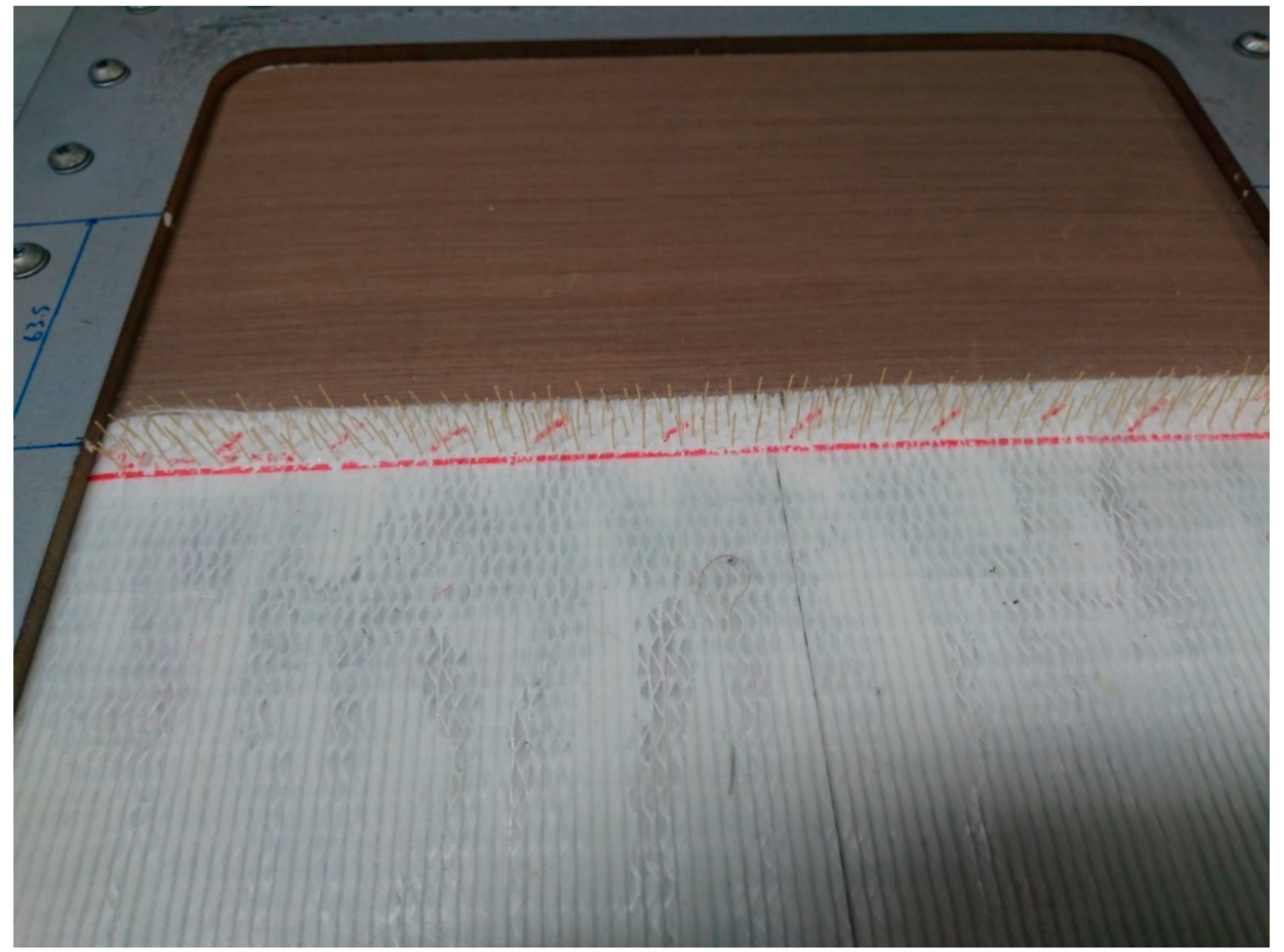

Figure 11. Case-4 samples prior to undergoing hot-press.

Once the array of pins was placed, the next challenge was conducting the hot press process. In prior works, the larger pinned region allowed sufficient integrity for the pinned part to be removed from the clamping frame with only the light friction from the fibers holding the pins in position. However, with the small overlap area, there was concern that this would be insufficient for these samples. It proved not to be.

The solution was to perform the hot-press process without removing the material from the frame. To do this, the part was pressed twice using a plate heated to $150{ }^{\circ} \mathrm{C}$ with pressure applied by means of a $5 \mathrm{~kg}$ weight placed on top. The first press retained the backstop used in the pinning process to prevent the pins from merely being pushed through the part. The second press followed the same setup; however, the underside of the part was supported again to prevent the pins from being pushed through the part. In both cases, a layer of Richmond Aerovac ETFE release film was used to prevent the powder epoxy adhering to the plate.

\section{Results/Discussion-Mechanical Properties}

\subsection{Lap Shear Tensile Testing}

The lap shear results are presented in Figure 12. A large lap shear strength reduction for VTFA400 commercial adhesive bonding was measured (-24.8\%) compared to the cured samples that are bonded with the powder epoxy. This behavior highlights the superior adhesive properties of the powder epoxy system for out-of-autoclave (OOA) manufacturing purposes. Indeed, the powder epoxy system was previously shown to have high fracture toughness [19] compared to standard epoxy prepregs. Additionally, the very low melt viscosity allowed for a homogeneous adhesion consolidation. 


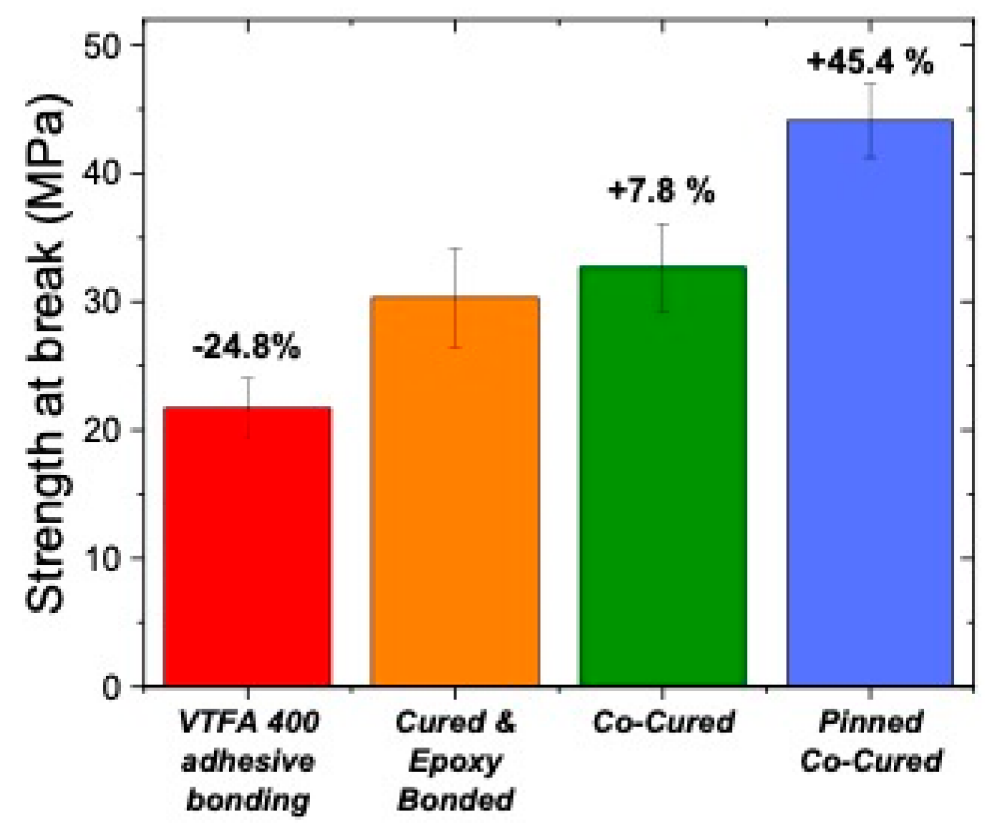

Figure 12. Lap shear strength at break for the four sets of samples.

Co-curing the plates has introduced both the abilities of covalent bonding and a better consolidation at the inter-plate region (adhesion surface), leading to a $+7.8 \%$ lap shear strength increase for co-cured compared to cured and bonded samples. This shear strength increase is attributed to both a better consolidation and crosslinking.

The through-thickness reinforcement pinning of uncured powder epoxy laminates, followed by co-curing, showed further substantial improvements, with a $+45.4 \%$ lap shear strength increase for pinned and co-cured compared to cured and bonded samples. This result highlights the ability to pin through the sintered/vitreous plates, and to then remelt and co-cure the powder epoxy around the pins, resulting in a superior consolidation. The mechanical viability of the pinning method was therefore demonstrated in this study.

\subsection{Digital Image Correlation (DIC)}

A comparison of typical damage mechanisms for each joint configuration can be inferred from digital image correlation (DIC). Specimen cross-sections were speckled with white spray paint spanning the full gauge length, to provide evenly distributed and high contrast tracking objects. A 12-megapixel Sony IMX477 sensor and Sill Optics Correctal $\mathrm{T} / 0.2 \mathrm{D}$ telecentric lens assembly was used to capture high-resolution orthographic images of the specimens during testing. For each sample type, three tests were recorded (H.264 video) at a $1080 \times 1920$ resolution and with a frame rate of 25 frames per second (fps). Video files were subsequently exported into image (.png) stacks with a 1:5 conversion ratio, resulting in an effective frame rate of $5 \mathrm{fps}$. Displacement and strain fields were calculated by importing image stacks into DICe open-source software by Sandia National Laboratories (SNL) [26]. For each analysis, the selected shape functions were translation, rotation, normal stretch, and shear stretch. An SSSIG threshold of 150, a 31-pixel subset size, and a 15-pixel step size were used for all analyses. The numerical error for this (2D-DICe) analysis is approximately $\pm 5 \%$ of the recorded value for elastic deformations [27].

Visualizations of the DIC results were produced using Paraview-5.9.1 open-source software. For each specimen, the DIC generated and imported an exodus (.e) file, and a Delaunay 2D-triangulation filter was applied. An alpha value of 22 was selected to populate the produced mesh. A Cauchy xy-shear strain and xx-longitudinal strain distributions of a representative sample for each manufacturing case are plotted in Figures 13 and 14, respectively. 


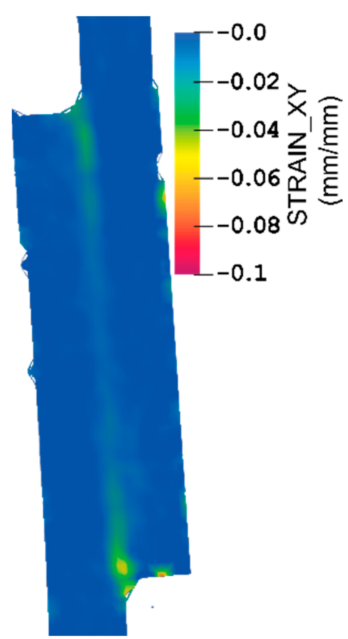

(a)

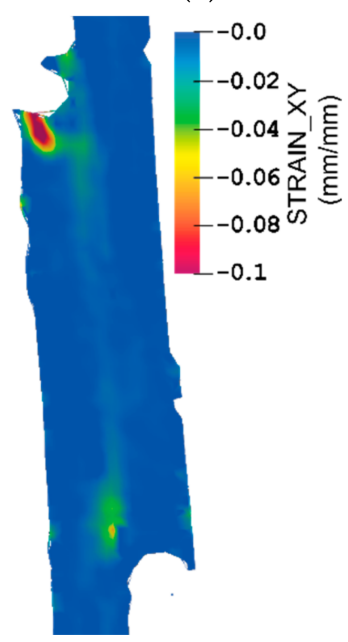

(c)

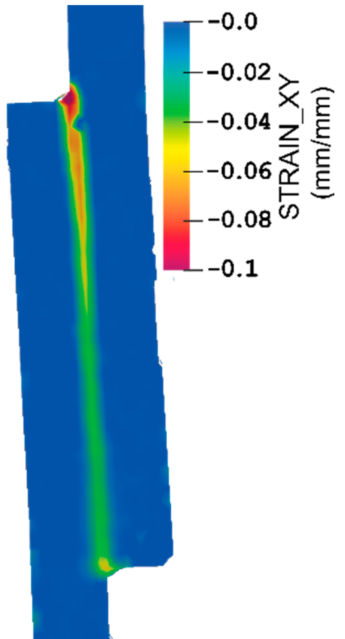

(b)

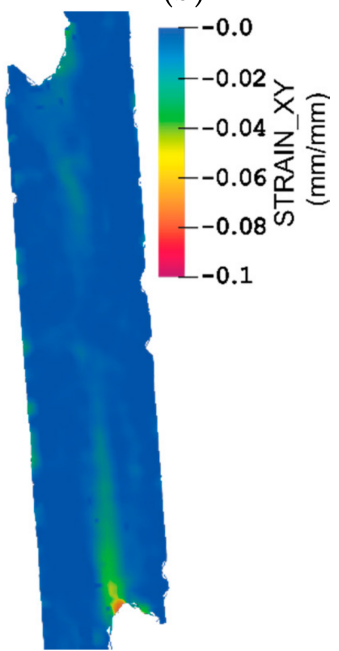

(d)

Figure 13. Pre-failure Cauchy strain_xy fields of representative (a) VTFA400 specimens (b) cured and bonded (c) co-cured; and (d) Z-pinned.

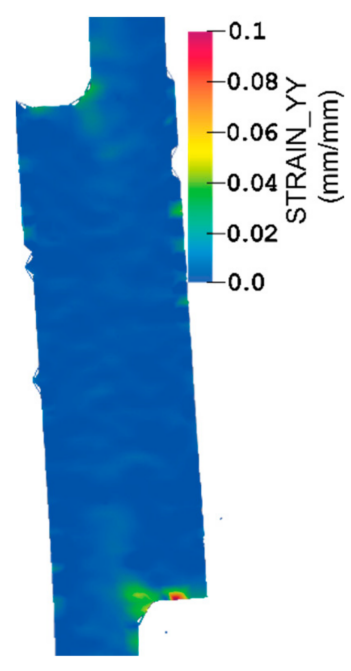

(a)

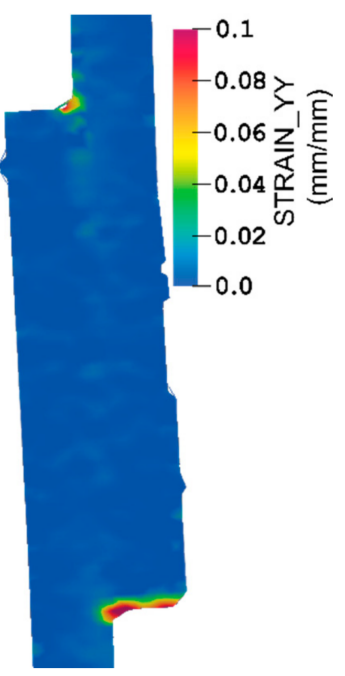

(b)

Figure 14. Cont. 


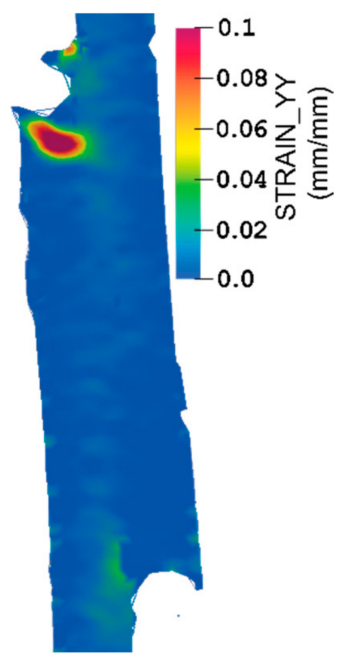

(c)

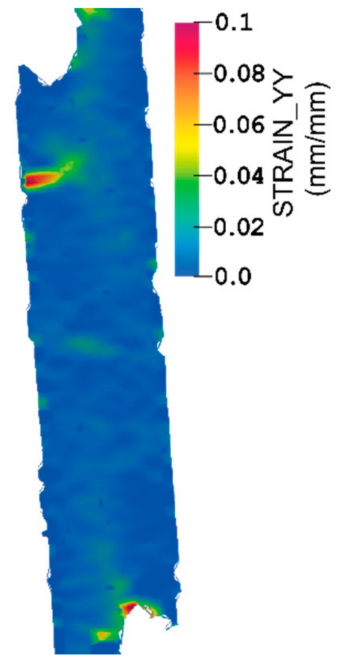

(d)

Figure 14. Pre-failure Cauchy strain_yy fields of representative (a) VTFA400 specimens (b) cured and bonded (c) co-cured; and (d) Z-pinned.

For each of the four representative specimens, observations were plotted at the frame prior to brittle failure, where the specimen strains were at peak magnitude. To facilitate straightforward comparisons between fields in Figures 13 and 14, distribution limits were defined as -0.1 to 0.0 and 0.0 to $0.1 \mathrm{~mm} / \mathrm{mm}$, respectively. For comparison, postfailure photographs of the same specimens are provided in Figure 15. In each of these images, the background was enhanced to improve contrast, and annotations were added where appropriate.

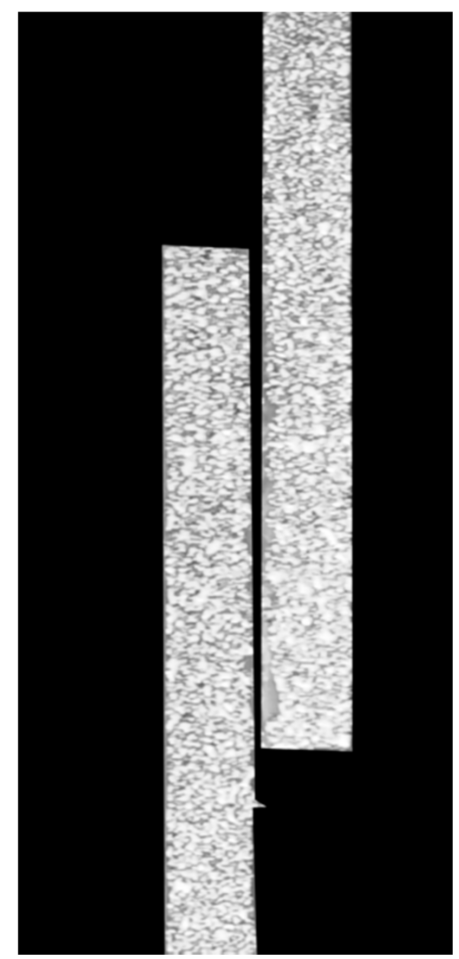

(a)

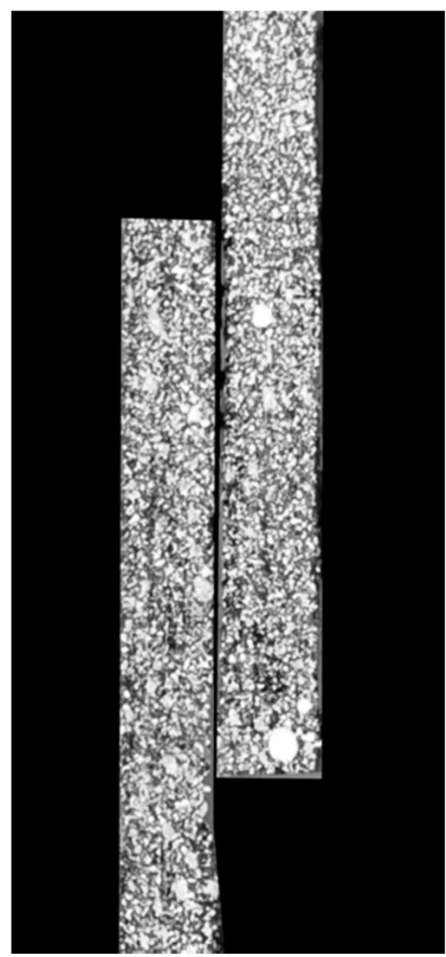

(b)

Figure 15. Cont. 


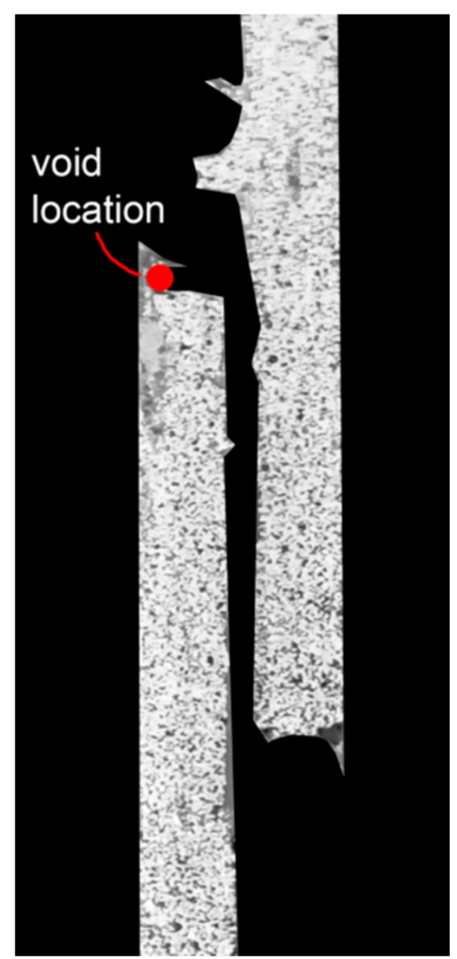

(c)

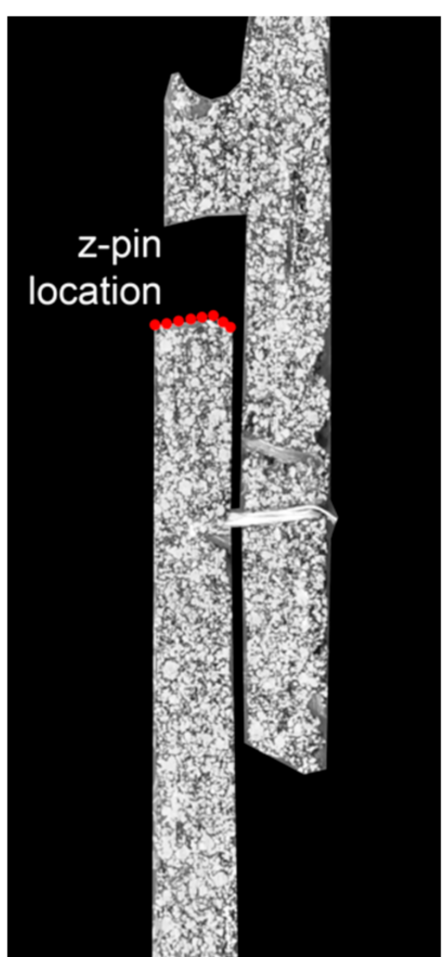

(d)

Figure 15. Post-failure images of representative (a) VTFA400 specimens (b) cured and bonded (c) co-cured; and (d) Z-pinned.

In observing the strain fields provided in Figures 13 and 14, local peaks can be associated with damage locations via the fractured specimen photographs in Figure 15. For all specimens, a shear strain peak occurs along the central bond line region with values generally largest at the upper and lower extremities. For both the cured and VTFA400 specimen types, these large shear and longitudinal strains correspond directly to points of damage initiation. As seen in Figure 15a,b, fracture in these bonded specimens has occurred entirely along the bond line via cohesive failure. The larger shear strain in the cured and bonded specimen is also anticipated, since the VTFA400 failure load is $24.8 \%$ lower. The co-cured specimen shows an oval shaped shear and longitudinal strain peak at the upper left corner of the lower adherend. This strain peak corresponds to a macro-void within the resin spew region and is present in certain co-cured samples. In considering Figure 15c, it can be discerned that a crack is initiated at the stress concentration around this void, extending horizontally until reaching the bond line and subsequently propagating downwards. Given the relatively low strains present across the remaining specimen cross section, it is possible that this mechanism may have caused minor premature failure in some co-cured samples. Similarly, the longitudinal strain distribution in Figure 14d indicates a high strain location at the upper left of the lower adherend in the Z-pinned representative specimen. Comparing the specimen strain distribution with the post-failure image in Figure 15d, it is apparent that damage has initiated at the location of a Z-pin and propagated along a similar path to the co-cured specimen. Although localized stress concentrations from Z-pinning are inevitable, larger load bearing capacities can still be achieved after further manufacturing process refinement [28].

\subsection{Fracture Behaviour}

Following testing, the lap shear samples were observed under a TM4000Plus scanning electron microscope (SEM) manufactured by Hitachi (Tokyo, Japan). Figure 16 shows the fracture surfaces under a magnification of 80 for all four sets of samples. The reinforcing mesh of the VTFA400 adhesive is clearly visible in Figure 16a as well as the glass fibre 
polyester stitching. In some areas, the raw fibers from the adherend are visible, suggesting an adhesive failure. However, in the bottom left of the figure, resin damage is clearly visible as well as the holes contained within the VTFA400 reinforcing mesh. This suggests a mixture of cohesive and adhesive failure for these specimens. Similar features are visible in Figure 16b for the cured and powder epoxy bonded samples with a mixture of adhesive and cohesive failure clearly visible in the fracture surface. However, there is a higher degree of resin damage on the surface of these samples which suggests a slightly better compatibility between the adhesive and adherend than for the VTFA400 samples, and could explain the higher measured lap shear strength.

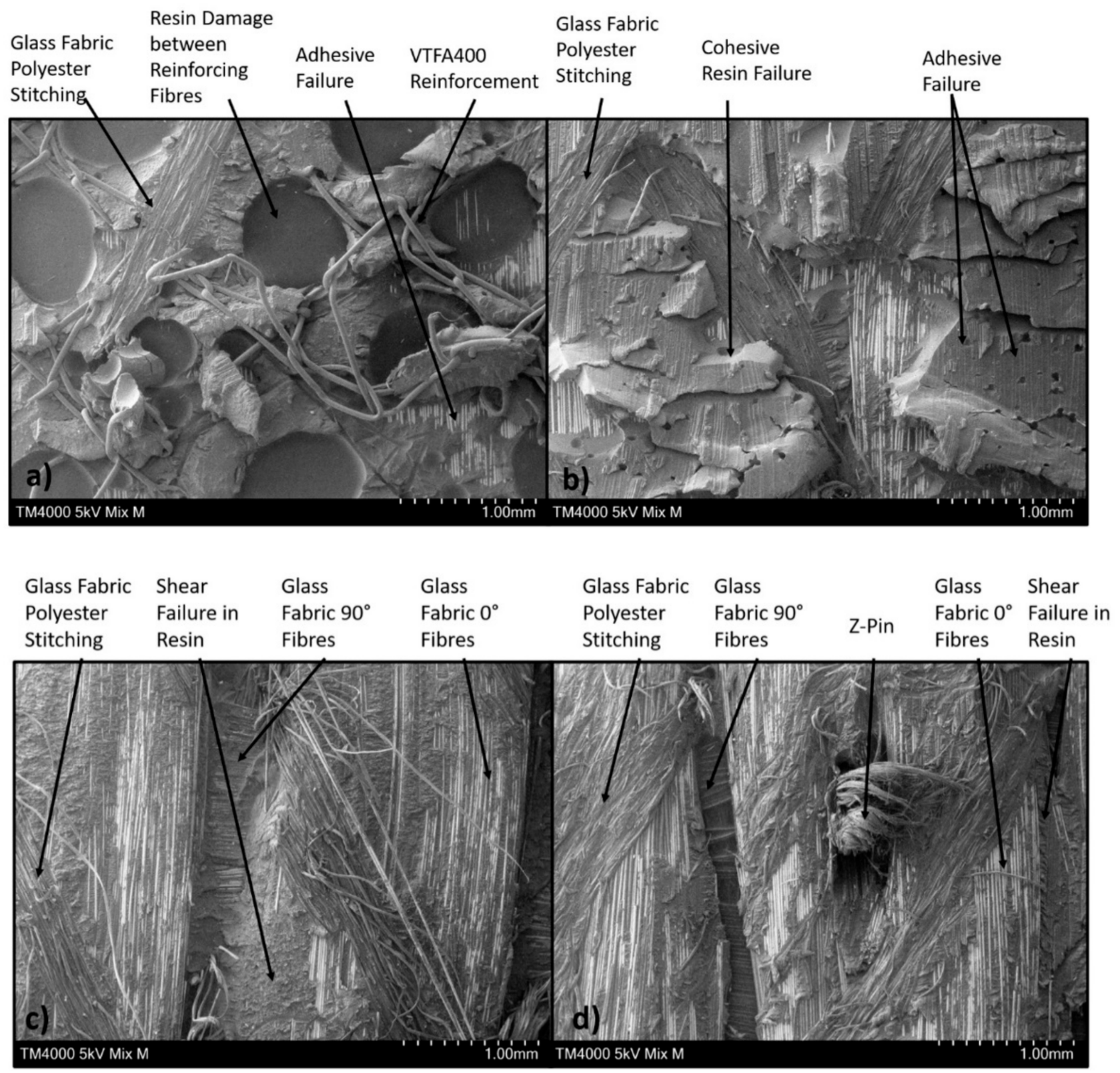

Figure 16. SEM Pictures of Fracture Surfaces with $\times 80$ Zoom for (a) VTFA400 Specimens (b) Cured and Bonded with Powder Epoxy (c) Co-cured and (d) Co-cured and Z-pinned.

The fracture surface of the co-cured and Z-Pinned samples are different from that of the first two specimens. Indeed, hardly any resin is visible on the fracture surfaces. The $0^{\circ}$, $90^{\circ}$, and polyester stitching from the glass fiber fabrics are visible from both Figure 16c, d. Resin was present in only small areas of the fracture surface. Observation of the resin areas 
under higher magnification revealed hackle patterns characteristic of shear failure [29]. The fracture surfaces of the co-cured and Z-pinned samples looked very similar apart from the presence of the Z-pins, as shown in Figure 16d. Co-curing of the resin has led to a very thin bond line and fiber migration within the bond. This explains why hardly any resin is present on the fracture surface while a large amount of fiber pull-out is visible. This explains the higher strength measured for these samples compared to the previous two sets. The presence of the Z-pins provides further reinforcement of the lap joint, but this is not characterized by significant differences in the fracture surface. Instead, the Z-pins delay the fracture phenomena occurring in the co-cured samples by resisting crack propagation, leading to a higher lap joint strength.

\section{Conclusions}

Glass fiber-reinforced powder epoxy plates were manufactured using a process developed in a previous study [19] and subsequently used to produce lap shear plates. The tensile lap-shear strength of the glass fiber reinforced powder epoxy lap shear plates was investigated, with results showing an increased load at break for co-curing methods compared to secondary bonding. Secondary bonding using VTFA400 had a load at break $24.8 \%$ lower than secondary bonding using powder epoxy. Co-curing increased the load at break by $7.8 \%$ compared to powder epoxy secondary bonding, with the co-cured and pinned joint resulting in a $45.4 \%$ increase in the load at break.

The typical damage mechanisms were investigated using digital image correlation. For secondary bonding using VTFA400 and powder epoxy, fracture occurred entirely along the bonding line via cohesive failure. Bonding using co-curing displayed premature failure in some samples related to macro voids in the resin spew area of the joint. The Z-pinned and co-cured joint showed damage around the Z-pin locations, which was to be expected; however, it is anticipated that, with further refinement of the manufacturing process, larger load bearing capacities could be achieved.

SEM indicated a mixture of cohesive and adhesive failure for the VTFA400 and powder epoxy bonded lap shear samples, with higher resin damage on the powder epoxy bond suggesting better compatibility of the adhesive and adherend. The co-cured and Z-pinned samples showed very similar fracture surfaces with very little resin, and indicated shear failure in resin areas, and that a large amount of fiber pullout had occurred. The Z-pinning provides further reinforcement to the lap joint, delaying the fracture phenomena and therefore resulting in the higher lap joint strength. Although a combination of DIC and SEM imaging have effectively indicated dominant fracture mechanisms from mechanical testing, a multiscale evaluation, such as that undertaken by Stukhlyak et al. [30], could provide a more in-depth understanding of damage mechanism in future investigations.

This initial study was a promising proof of concept to demonstrate the advantages of the powder epoxy resin when combined with co-curing and pinned joining methods. The very specific processing properties of the powder epoxy system allowed to show the best of both thermoset (low viscosity, better co-curing mechanical properties) and thermoplastic (non-brittle pinning on complex structures, higher toughness), allowing co-curing and pinning all at once, leading to vastly superior mechanical properties when combined.

Overall, the powder epoxy resin has a range of advantages, making it a suitable candidate for the co-curing of large composite structures. Future work will involve employing the co-curing and pinning bonding methods on more complex structures, for example on thick section composites such as tidal turbine blades. Automated applications, such as additive manufacturing, will also be considered. There will be the ability to locally change the polymeric properties to meet specific requirements, e.g., erosion protection [31].

Author Contributions: Concept, C.M.Ó.B., E.A. and C.R.; Methodology, E.A., C.R., T.N., T.D. and W.M.; Software, J.R.D.; Investigation, C.R., C.F., J.R.D. and A.B.; Formal analysis, T.N. and C.R.; Review and editing, C.M.Ó.B., E.A., C.R., C.F., J.R.D., A.B., W.M., A.M. and T.D.; Supervision, C.R.; Funding acquisition, C.R., E.A. and A.M. All authors have read and agreed to the published version of the manuscript. 
Funding: The authors gratefully thank the EPSRC Future Composites Manufacturing Research Hub for its financial contribution to this project. EPSRC reference number: EP/P006701/1.

Institutional Review Board Statement: Not applicable.

Informed Consent Statement: Not applicable.

Data Availability Statement: The authors are happy to share the data on request.

Acknowledgments: Swiss CMT + Freilacke for the provision of the powder epoxy (PE6405).

Conflicts of Interest: The authors declare no conflict of interest.

\section{References}

1. Harshe, R. A review on advanced out-of-autoclave composites processing. J. Indian Inst. Sci. 2015, 95, $207-220$.

2. Centea, T.; Grunenfelder, L.K.; Nutt, S.R. A review of out-of-autoclave prepregs-Material properties, process phenomena, and manufacturing considerations. Compos. Part A 2015, 70, 132-134. [CrossRef]

3. Armanios, E.; Bucinell, R.; Wilson, D.; Hart-Smith, L. Adhesive bonding of composite structures-Progress to date and some remaining challenges. J. Compos. Technol. Res. 2002, 24, 133. [CrossRef]

4. Budhe, S.; Banea, M.D.; de Barros, S.; da Silva, L. An updated review of adhesively bonded joints in composite materials. Int. J. Adhes. Adhes. 2017, 72, 30-42. [CrossRef]

5. SAE International on behalf of CMH-17. Design and analysis of bonded joints. In Composite Materials Handbook-17 (CMH-17); SAE International on behalf of CMH-17, A Division of Wichita State University: Warrendale, PA, USA, 2012; Volume 3, pp. 10-1-10-3.

6. Dillingham, R.G. Composite bond inspection. In Structural Integrity and Durability of Advanced Composites; Beaumont, P.W.R., Soutis, C., Hodzic, A., Eds.; Woodhead Publishing: Cambridge, UK, 2015; pp. 695-706.

7. Fuertes, T.A.S.; Kruse, T.; Körwien, T.; Geistbeck, M. Bonding of CFRP primary aerospace structures-Discussion of the certification boundary conditions and related technology fields addressing the needs for development. Compos. Interfaces 2015, 22, 795-808. [CrossRef]

8. Hasan, Z.; Rader, J.; Olson, A.; Turpin, D.; Onge, R.S.; Amback, J. Design, analysis and fabrication of thick co-cured wing structures. Compos. Part B Eng. 2019, 177, 107335. [CrossRef]

9. Huang, C. Study on co-cured composite panels with blade-shaped stiffeners. Compos. Part A Appl. Sci. Manuf. 2003, 34, 403-410. [CrossRef]

10. Riley, B.L. AV-SB/GR Mk 5 airframe composite applications. Proceedings of the institution of mechanical engineers, part D: Transport engineering. SAGE J. 1986, 200, 167-183.

11. National Aeronautics and Space Administration. Composite Chronicles: A study of the Lessons Learned in the Development, Production, and Service of Composite Structures; NASA Contractor Report 4620; NASA: Washington, DC, USA, 1994.

12. Kageyama, M.; Yoshida, S. Development of XF-2 fighter composite structures (co-cured composite wings). In Proceedings of the 41st AIAA Structures, Structural Dynamics, and Materials Conference and Exhibit, Atlanta, GA, USA, 3-6 April 2000.

13. Patterson, J.B. One-shot Manufacturing Techniques Developed for Carbon Fiber Prepreg Components. Ph.D. Thesis, Lehigh University, Bethlehem, PA, USA, 2018.

14. Maguire, J.M.; Nayak, K.; Ó Brádaigh, C.M. Characterisation of epoxy powders for processing thick-section composite structures. Mater. Des. 2018, 139, 112-121. [CrossRef]

15. Maguire, J.M.; Roy, A.S.; Doyle, D.; Logan, M.; Ó Brádaigh, C.M. Resin characterisation for numerical modelling of throughthickness resin flow during out of autoclave processing of thick-section wind or tidal turbine blades. In Proceedings of the 20th International Conference on Composite Materials, Copenhagen, Denmark, 19-24 July 2015; ICCM 20. Thomsen, O.T., Berggreen, C., Sørensen, B.F., Eds.; Aalborg University: Aalborg, Denmark, 2015.

16. Robert, C.; Pecur, T.; Maguire, J.M.; Lafferty, A.D.; McCarthy, E.D.; Ó Brádaigh, C.M. A novel powder-epoxy towpregging line for wind and tidal turbine blades. Compos. Part B Eng. 2020, 203, 108443. [CrossRef]

17. Robert, C.; Mamalis, D.; Alam, P.; Lafferty, A.D.; Cadhain, C.Ó.; Breathnach, G.; McCarthy, E.D.; Ó Brádaigh, C.M. Powder Epoxy Based UD-CFRP Manufacturing Routes for Turbine Blade Application; SAMPE: Southampton, UK, 2018.

18. Glennon, C.; Flanagan, T.; Doyle, A.; Kelly, G.; Ó Brádaigh, C.M.; Finnegan, W. Development of Novel Manufacturing Techniques for Composite Tidal Turbine Blades; SAMPE: Southampton, UK, 2018.

19. Floreani, C.; Robert, C.; Alam, P.; Davies, P.; Ó Brádaigh, C.M. Mixed-mode interlaminar fracture toughness of glass and carbon fibre powder epoxy composites-For design of wind and tidal turbine blades. Materials 2021, 14, 2103. [CrossRef] [PubMed]

20. Bump, M.M.B. The Effect of Chemistry and Network Structure on Morphological and Mechanical Properties of Diepoxide Precursors and Poly(Hydroxyethers). Ph.D. Thesis, Faculty of the Virginia Polytechnic Institute, Virginia Polytechnic Institute and State University, Blacksburg, VA, USA, 2001.

21. Floreani, C.; Cuthill, F.; Steynor, J.; Maguire, J.; McCarthy, E.D.; Niessink, M.J.; Di Noi, S.; Wittevrongel, L.; Flanagan, T.; Ó Brádaigh, C.M. Testing of a $6 \mathrm{~m}$ hybrid glass/carbon fibre powder epoxy composite wind blade demonstrator. SAMPE J. 2021, 6, 6-14.

22. SAERTEX®. U-E-591g/m2-1200mm Technical Datasheet; SAP No. 30001209; SAERTEX: Saerbeck, Germany, 2021. 
23. Reddy, S.S.P.; Suresh, R.; Hanamantraygouda, M.B.; Shivakumar, B. Use of composite materials and hybrid composites in wind turbine blades. Mater. Today Proc. 2021, 46, 2827-2830. [CrossRef]

24. Structural Adhesives, Part II: Aerospace. Available online: https://www.compositesworld.com/articles/structural-adhesivespart-ii-aerospace (accessed on 17 June 2021).

25. Archer, E.; Mcllhagger, A.; Dixon, D.; Ralph, C.; Dooher, T.; Mosses, W. Controlled Micro Integration of Through Thickness Polymeric Yarns. 2019. Available online: https://cimcomp.ac.uk/wp-content/uploads/2019/08/Final-report-on-micro-extrusion_3. pdf (accessed on 23 June 2021).

26. Turner, D.; Crozier, P.; Reu, P. Digital Image Correlation Engine v.3.0. Digit. Image Correl. Engine (DICE) Ref. Man. 2015. [CrossRef]

27. Buck, N.V. Implementation of an Open-Source Digital Image Correlation Software for Structural Testing. Master's Thesis, California Polytechnic State University, San Luis Obispo, CA, USA, 2020.

28. Chang, P.; Mouritz, A.; Cox, B. Tensile Strength and Fatigue Properties of Z-Pinned Composite Lap Joints; Woodhead Publishing: Cambridge, UK, 2004; pp. 615-620. [CrossRef]

29. Bonhomme, J.; Argüelles, A.; Viña, J.; Viña, I. Fractography and failure mechanisms in static mode I and mode II delamina-tion testing of unidirectional carbon reinforced composites. Polym. Test. 2009, 28, 612-617. [CrossRef]

30. Stukhlyak, P.D.; Buketov, A.V.; Panin, S.V.; Maruschak, P.O.; Moroz, K.M.; Poltaranin, M.A.; Vukherer, T.; Kornienko, L.A.; Lyukshin, B.A. Structural fracture scales in shock-loaded epoxy composites. Phys. Mesomech. 2015, 18, 58-74. [CrossRef]

31. Hassan, E.; Zekos, I.; Jansson, P.; Pecur, T.; Floreani, C.; Robert, C.; Ó Brádaigh, C.M.; Stack, M. Erosion mapping of throughthickness toughened powder epoxy gradient Glass-Fiber-Reinforced Polymer (GFRP) plates for tidal turbine blades. Lubricants 2021, 9, 22. [CrossRef] 